\title{
Building Information Modeling for Environmental Impact Assessment in Early Design Phases: A Literature Review
}

\author{
Marie-France Stendahl ${ }^{1 *}$, Marie-Claude Dubois' ${ }^{1}$, Daniel Forgues ${ }^{2}$, Eilif Hjelseth ${ }^{3}$ \\ ${ }^{1}$ Architecture and the Built Environment, Division of Energy and Building Design, Lund University (LTH), Lund, Sweden \\ ${ }^{2}$ Department of Construction, University of Quebec, École de Technologie Supérieure (ÉTS), Montréal, Canada \\ ${ }^{3}$ Department of Civil and Environmental Engineering, Faculty of Engineering, Norwegian University of Science and Technology \\ (NTNU), Trondheim, Norway \\ Email: ^marie-france.stendahl@ebd.lth.se
}

How to cite this paper: Stendahl, M.-F., Dubois, M.-C., Forgues, D. and Hjelseth, E. (2022) Building Information Modeling for Environmental Impact Assessment in Early Design Phases: A Literature Review. Open Journal of Applied Sciences, 12, 59-81. https://doi.org/10.4236/ojapps.2022.121006

Received: December 3, 2021

Accepted: January 10, 2022

Published: January 13, 2022

Copyright $\odot 2022$ by author(s) and Scientific Research Publishing Inc. This work is licensed under the Creative Commons Attribution International License (CC BY 4.0).

http://creativecommons.org/licenses/by/4.0/

\begin{abstract}
The building sector is the largest consumer of energy in industrial countries. Saving energy in new buildings or building renovations can thus lead to significant global environmental impacts. In this endeavor, building information modeling (BIM) and building energy modeling (BEM) are two important tools to make the transition to net-zero energy buildings (NZEB). So far, little attention has been devoted, in the literature, to discuss the connection between BIM, BEM, and Life-cycle assessment (LCA), which is the main topic of this article. A literature review of 157 journal articles and conference proceedings published between 1990 and 2020 is presented. This review outlines knowledge gaps concerning BIM, BEM, and environmental impact assessment. It suggests that defining the process with the right technology (at the right time) would result in a more integrated design process (IDP) and bridge current gaps. The most efficient way to improve process and technology is related to the competences of the architects, engineers and constructors (AEC). The review also indicates that the IDP in the early design phases (EDP) is in need of improvement for architects and engineers, where a better connection between design phases, specific levels of development (LOD) and BIM tools is needed. Competences, process and technology are the three main themes addressed in the review. Their relation to design phases and LOD is discussed. The aim is to propose possible solutions to the current hinders in BIM-to-BEM (BIM2BEM) and BIM-for-LCA (BIM4LCA) integration.
\end{abstract}

\section{Keywords}

Building Information Modeling (BIM), Building Energy Modeling (BEM), 
Life Cycle Assessment (LCA), Simulations, Energy, Carbon, Design Process, Design Phases, Level of Development

\section{Introduction}

Globally, of all sectors of the economy, the building sector is responsible for more than $30 \%$ of energy use [1]. According to the international energy agency (IEA), the building sector also accounts for nearly $30 \%$ of energy-related carbon dioxide $\left(\mathrm{CO}_{2}\right)$ emissions [2]. Earlier studies have shown that, in developed countries, the building sector is even the largest consumer of energy [3] [4]. For instance, in the United States, buildings are responsible for approximately $40 \%$ of total energy consumption and $30 \%$ of annual greenhouse gas (GHG) emissions. Reducing building energy use by a small percentage thus leads to significant global environmental impacts.

The demand for a more sustainable built environment with energy-efficient buildings is thus on the rise. As stated by Asl et al. [5], "integrating performance metrics such as energy use and material consumption can make the transition towards near-zero or carbon neutral buildings a reality". The shift to carbon neutral buildings requires that $\mathrm{CO}_{2}$ emissions (from operational energy use and embodied energy in the production, transportation and assembly of building materials) need to be compensated for by renewable energy production on site during a number of years. An alternative, more controversial, method is the purchase of carbon credits, meaning that the $\mathrm{CO}_{2}$ is avoided somewhere else on Earth through carbon capture storage (e.g. planting trees) or renewable energy production (e.g. solar energy parks, etc.). As a world leader in this endeavor, the European Union (EU) established a legislative framework called the energy performance of buildings directive (EPBD). The EPBD pursues the goal to significantly improve the energy performance of buildings by establishing a set of rules and definitions taking into account outdoor climatic and local conditions, indoor climate requirements as well as cost-effectiveness. In addition, the EPBD creates a stable environment for investors, while enabling consumers and businesses to make more informed choices which promote energy conservation [6] [7].

One method to validate the EPBD is through the use of building energy modeling (BEM), which requires full integration with building information modeling (BIM) to be compatible with the current building practice. The Life-cycle assessment (LCA) history arose due to the concern of experts about the anticipated limitation of energy resources. Supporting design decisions based on BEM with the goal to produce energy-efficient and sustainable buildings is a relatively recent trend in design practice. Eurac research about regenerative design in digital practice [8] emphasized that "modeling can be used to keep track of how a single design has an impact on the natural world, and how the natural world could inspire design, giving way to new and innovative methods of bringing sustainabil- 
ity into a practice's structure". In the future, this integration will play a key role to accelerate the transition to net-zero energy buildings (NZEB) and reach global climate neutrality.

Despite the fact that BIM was originally developed for its potential for energy and environmental impact assessments, the scientific literature on this subject suggests that this integration is currently suboptimal and even dysfunctional, which is a bottleneck for the design and construction industry. Furthermore, as outlined by Picco and Marengo [9], better integration of the design process necessarily requires a stronger collaboration between engineers and architects, leading to a better exchange of content and information with the spirit of the integrated design process (IDP). They also mentioned that the use of ES can provide information to support IDP that would not be available otherwise and there is a need to minimize the time required for the analysis to be compatible with IDP. Figure 1 compares traditional design process and IDP in relation to effort/effect over time [10].

The success of BIM-to-BEM (BIM2BEM) and BIM-for-LCA (BIM4LCA) integration, depends on three key ingredients: competences, process and technology, as elaborated further down. BIM involves process and technology as well as people (competences) and regulations. As explained by Farzaneh et al. [11], most existing BIM2BEM and BIM4LCA frameworks do not simultaneously describe the process and the technology to use during each design phase. Gomes et al. [12] also claimed that a clearer process is needed to reduce the risk of errors, while facilitating BIM4LCA by enabling an automatic extraction of material quantities.

Improving competences and a closer collaboration between architects, engineers and constructors (AEC) is also critical for the development of work processes with the right tools in the different design phases, which will ultimately support a more accurate and cost-effective design process. In order to fill the

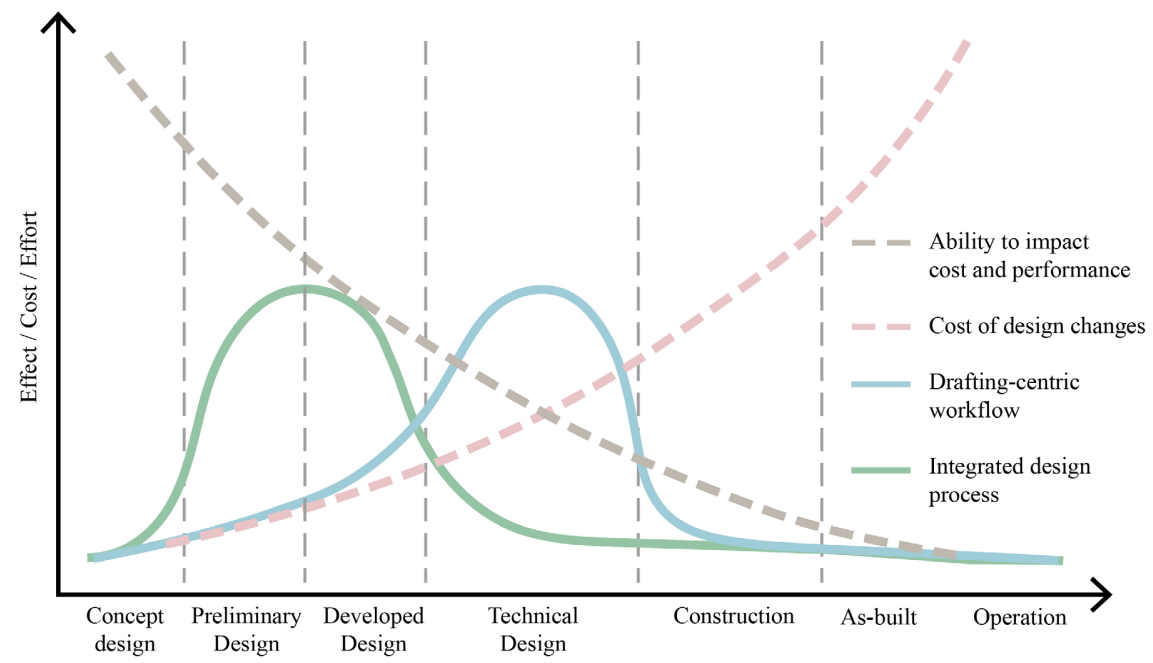

Figure 1. Moving towards an IDP approach, adapted from Patrick Macleamy AIA/HOK 2009. 
identified gaps relating to competences, process and technology, a more comprehensive and general approach needs to be developed, especially in the EDP.

This article investigates the integration between BIM, BEM and LCA. The thesis pursues the goal to identify gaps related to technology, process and competences and propose possible areas of development or solutions to the identified gaps. The review reveals that a combination of: 1) improving competences, 2 ) defining and describing the process, and 3) using the right technology at each design phase, are the main steps towards improving the BIM2BEM and BIM4LCA integration. The next publication will discuss results of interviews and surveys about the current BIM2BEM and BIM4LCA integration in different architectural and engineering practices.

\section{Key Definitions}

For clarity, a few key definitions of concepts presented in this article are provided below.

Building energy modeling (BEM) refers to software simulation based on heat transfer and building physics in combination with information retrieved from local weather files, including e.g. temperatures, solar radiation, wind speeds, etc. [13]. The first method introduced in the $50 \mathrm{~s}$ was the steady-state method. The development continued with the introduction of dynamic ES [14].

Building information modeling (BIM) is the collaborative process between AEC on an intelligent 3D model that provides tools to handle planning, design and construction more effectively. The first 3D model appeared in the late 1970s although the term BIM has only been recognized in the last twenty years after it became a universally agreed term with different countries developing standards of practice [10].

$\mathrm{CO}_{2}$ emissions refer to the conversion of operational energy demand and embodied energy using equivalence factors for carbon dioxide $\left(\mathrm{CO}_{2} \mathrm{eq}\right)$.

Dynamic ES refers to simulations involving climate file with data for each hour of the year as input to the thermal simulations [14].

Embodied emissions refer to the GHG emissions released by embodied energy use.

Embodied energy is the energy consumption required to produce the building capital. It refers to the energy consumed to extract, refine, process, transport and fabricate a material or product included in buildings [15].

Integrated Design Process (IDP) refers, in contrast to the conventional linear design process, to a design process to accomplish high performance sustainable buildings with multidisciplinary teams that collectively agree on environmental targets, as defined in the guideline for the IDP from IEA [16]. They also agree on methods (e.g. simulations) that will be used to meet these highperformance targets.

Level of development (LOD) is a system that allows the AEC industry to specify the content and validity of BIM at different stages and articulate the de- 
sign and construction process with a high level of clarity [10].

Figure 2 shows the LOD scheme that consists of six levels, namely, LOD 100, $200,300,350,400,500$ and 600 . For each LOD, a type of model is specified with the level of information contained to facilitate data exchange between professionals involved in the design process [12]. Table 1 shows the specifications of each LOD.

Life-cycle assessment (LCA) is defined as the process by which environmental impacts (including impacts of energy use for building operation), are assessed for all stages of the building's life cycle using a scientific methodology.

Table 1. Specifications of the LOD [22].

\section{LOD 100-Conceptual}

Elements are not geometric presentations. They may be symbols or other generic representations of information that can be derived from other model elements. Any information derived from LOD 100 elements must be considered approximate.

LOD 200-Approximate Geometry

Elements are graphic representations of generic placeholders for volume, quantity, location, or orientation information. Any information derived from LOD 200 elements must be considered approximate.

\section{LOD 300-Precise Geometry}

Elements are graphically represented as specific systems, objects or assemblies: quantity, shape, size, location, and orientation can be measured directly, without having to refer to non-modelled information such as notes or dimension callouts.

\section{LOD 350-Precise Geometry with Connections}

Elements are enhanced beyond LOD 300 by the addition of information regarding coordination interfaces with other building systems. For example, a LOD 350 masonry wall element would include jamb conditions, bond beams, grouted cells, dowel locations, and joints.

\section{LOD 400-Fabrication/Ready Geometry}

Elements are modelled at enough detail and accuracy for fabrication of the represented component.

\section{LOD 500-Operational/As-built Models}

Elements are modelled as constructed assemblies for operation and maintenance. Non-geometric information is attached to modelled elements that are actual and accurate in size, shape, location, quantity and orientation.

\section{LOD 600-Operate}

Elements are $100 \%$ geometric presentations. Services and BIM model updated such as displacement or damage.

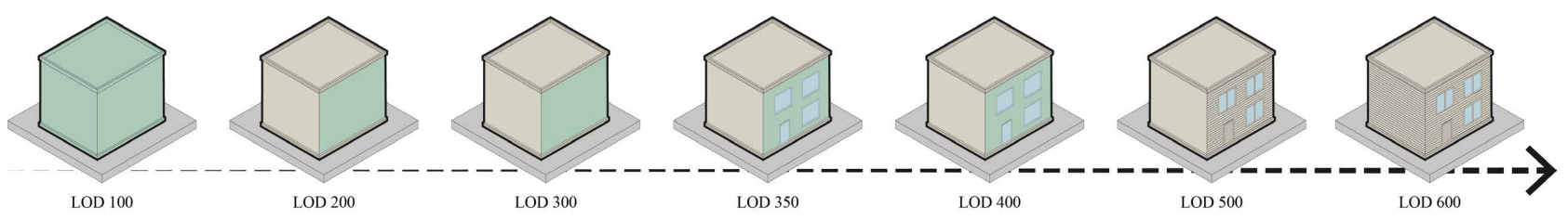

Figure 2. Interpretation of the LOD definitions, adapted from [21]. 
The calculation shows how the building affects the environment through its whole life cycle i.e. from extraction of materials to their disposal [17].

Operational energy (heating, ventilation and cooling (HVAC)) is calculated using the concept of primary energy, which includes all emissions for extraction, processing, generation, storage, transport, distribution, and delivery of energy [18].

Process is defined a series of actions and decisions directed to produce and communicate results [19].

Steady-state calculations refer to calculations based on a constant temperature difference and the degree-day method [14].

Technology refers to the creation and use of technical means and their interrelation with the environment [20].

The LOD definitions were established in 2008 by the American Institute of Architects (AIA). They were subsequently updated in 2013. The LOD are used in countries like Germany, France, Australia, Canada, China, Singapore and Taiwan based on AIA protocols. In the UK, the LOD includes Level of Detail, the amount of detail contained within the graphical parts of a model, and include Level of Information (LOI), i.e. the amount of detail contained within the nongraphical parts of a model-the Data [23]. LOD is the degree the components specification and attached information that have been resolved [10].

\section{Method}

\subsection{Research Methodology}

For the development of this study, a bibliometric analysis technique was adopted. As stated by Marsilio et al. [24], "bibliometric method attempts to quantify and address the intellectual structure of a research field starting from the mathematical and statistical analysis of patterns that appear in the publication and use of documents".

\subsection{Literature Search Strategy}

The scientific databases to search were determined based on experience and earlier published research results. The databases Web of Science, Scopus and a multiple database tool, LUB search, were used. LUB search is Lund University library multiple database research tool.

Articles from journals and conference proceedings, published since 2006 were found using the search terms "BIM AND BEM", " $L C A$ ", "simulations", "energy", "carbon", "design process", "design phases", "level of development”. A total of 157 articles were identified and downloaded in EndNote. The articles were scrutinized and reading notes were collected, saved in the Microsoft Word program, and indexed in the Microsoft Excel program. Reading notes consisted of a one A4 page of information regarding four main aspects: 1) aim of the research 2) methodology 3) main results and conclusions obtained 4) limitations of the research. Four (4) articles were excluded since they were found to be unrelated 
to the research topic, 21 articles were excluded from further analysis as they failed to meet the inclusion criteria, i.e. knowledge gaps concerning BIM and environmental impact assessment, and 48 articles were saved for a second round because they did not meet all the inclusion criteria. Table 2 shows the indexed corpus profile.

\subsection{Analysis of Relevant Literature}

A total of 84 articles (61 articles from 30 academic journals and 23 from 14 relevant conferences) were read and analyzed. Most articles were published in journals such as "Automation in Construction", "Energy and Buildings" and "Journal of Building Engineering", while several papers were published in "Education and research in Computer Aided Architectural Design in Europe (eCAADe)", "International Building Performance Simulation Association (IBPSA)" and "Sustainable Built Environment (SBE)". Table 3 shows reviewed sources from 2006 to present.

\section{Results}

The literature review procedure primarily involved the classification of the articles according to their main purpose, considering three recurrent themes:

- Competences,

- Process,

- Technology.

This review leads to suggest that these main themes need to be further developed to accomplish the IDP. This article is organized according to these themes and relates them to three subthemes also identified in the literature:

- Design phases from EDP (including concept design, preliminary design and developed design) to construction documentation, fabrication, assembly and as built,

- LOD,

- BIMT including automation, interoperability, datasets, clouding, digital fabrication, Internet of things (IoT), and digital twins.

Table 2. Indexed corpus profile.

\begin{tabular}{ccc}
\hline Profile & Number of papers & Percentage (\%) \\
\hline $\begin{array}{c}\text { Total publication in Web of } \\
\text { Science, Scopus, LUB search } \\
\text { Paper excluded found to be } \\
\text { unrelated to the research }\end{array}$ & 157 & 100 \\
$\begin{array}{c}\text { Paper excluded as they failed to } \\
\text { meet the inclusion criteria }\end{array}$ & 4 & 13 \\
$\begin{array}{c}\text { Paper saved for as second round } \\
\text { not meeting all the inclusion criteria } \\
\text { Total papers to be analyzed for } \\
\text { the guided study research }\end{array}$ & 48 & 30 \\
\hline
\end{tabular}


Table 3. Review sources from 1990 to 2020.

\begin{tabular}{|c|c|c|}
\hline & Journals & Number of articles \\
\hline 1 & Advances in Architectural Geometry (book) & 1 \\
\hline 2 & Applied Energy & 1 \\
\hline 3 & Applied Mechanics and Materials & 1 \\
\hline 4 & Architectural Science Review & 1 \\
\hline 5 & Arquitetura Revista & 1 \\
\hline 6 & Automation in Construction & 11 \\
\hline 7 & Building and Environment & 1 \\
\hline 8 & Building Research \& Information & 1 \\
\hline 9 & Computer-Aided Design & 1 \\
\hline 10 & Energies & 1 \\
\hline 11 & Energy and Buildings & 9 \\
\hline 12 & Energy Procedia & 1 \\
\hline 13 & International Journal of Project Management & 1 \\
\hline 14 & $\begin{array}{l}\text { International Journal of Sustainable } \\
\text { Development and Planning }\end{array}$ & 2 \\
\hline 15 & $\begin{array}{l}\text { International Research Journal of } \\
\text { Engineering and Technology }\end{array}$ & 1 \\
\hline 16 & Journal of Architecture Engineering & 1 \\
\hline 17 & $\begin{array}{l}\text { Journal of Asian Architecture and } \\
\text { Building Engineering }\end{array}$ & 1 \\
\hline 18 & Journal of Building Engineering & 4 \\
\hline 19 & Journal of Building Performance Simulation & 1 \\
\hline 20 & Journal of Civil Engineering and Management & 1 \\
\hline 21 & Journal of Cleaner Production & 2 \\
\hline 22 & Journal of Energy Systems & 1 \\
\hline 23 & Journal of Engineering and Architecture & 1 \\
\hline 24 & Periodica Polytechnica Architecture & 1 \\
\hline 25 & $\begin{array}{l}\text { Pós. Revista do Programa de Pós-Graduação em } \\
\text { Arquitetura e Urbanismo da FAUUSP }\end{array}$ & 1 \\
\hline 26 & Procedia CIRP & 2 \\
\hline 27 & Procedia Engineering & 6 \\
\hline 28 & Renewable and Sustainable Energy Reviews & 2 \\
\hline 29 & Sustainability & 2 \\
\hline \multirow[t]{2}{*}{30} & The Scientific World Journal & 1 \\
\hline & Total & 61 \\
\hline
\end{tabular}




\section{Continued}

\begin{tabular}{|c|c|c|}
\hline & Conferences & Number of articles \\
\hline 1 & $\begin{array}{l}\text { Association of Collegiate Schools of } \\
\text { Architecture ACSA }\end{array}$ & 1 \\
\hline 2 & $\begin{array}{l}\text { Building Performance Analysis } \\
\text { Conference \& Sim Build }\end{array}$ & 1 \\
\hline 3 & Central Europe towards Sustainable Building CESB & 1 \\
\hline 4 & Computer-Aided Design CAD & 1 \\
\hline 5 & Computing in Civil Engineering & 1 \\
\hline 6 & Creative Construction Conference CCC & 1 \\
\hline 7 & CISBAT & 2 \\
\hline 8 & $\begin{array}{l}\text { Cost Reduction and market Acceleration for } \\
\text { Viable nearly zero-Energy buildings CRAVEzero }\end{array}$ & 1 \\
\hline 9 & $\begin{array}{l}\text { Education and research in Computer Aided } \\
\text { Architectural Design in Europe eCAADe }\end{array}$ & 3 \\
\hline 10 & $\begin{array}{l}\text { International Building Performance Simulation } \\
\text { Association IBPSA }\end{array}$ & 4 \\
\hline 11 & $\begin{array}{c}\text { International Symposium on Automation and } \\
\text { Robotics in Construction ISARC }\end{array}$ & 1 \\
\hline 12 & $\begin{array}{l}\text { Simulation for Archietcture and } \\
\text { Urban Design SimAUD }\end{array}$ & 1 \\
\hline 13 & SOLARIS & 1 \\
\hline \multirow[t]{2}{*}{14} & Sustainable Built Environment SBE & 4 \\
\hline & Total & 23 \\
\hline
\end{tabular}

Figure 3 presents the structure of the themes and subthemes addressed in the scientific literature. The digital plan of work of the Architects' Council of Europe (ACE) was chosen to describe the design phases due to its detailed EDP compared to e.g. the Royal Institute of British Architects (RIBA), which only includes concept design and spatial coordination in the EDP. Additionally, although RIBA is the only plan of work incorporating BIM and sustainability, there is currently no set of recommendations about LOD for each stage in architecture [25].

In addition to the identified themes and subthemes, this review indicates the main areas that require improvements. We propose a model in EDP to allow a better connection between LOD and BIMT in BIM2BEM and BIM4LCA integration. For example, we propose that BIM and automation should be related to LOD 100 in the concept design phase, BIM2BEM and interoperability should be related to LOD 200 in preliminary design phase, while BIM4LCA and datasets should be related to LOD300 in the developed design phase. This article focuses on the EDP above the dotted line in Figure 3. 

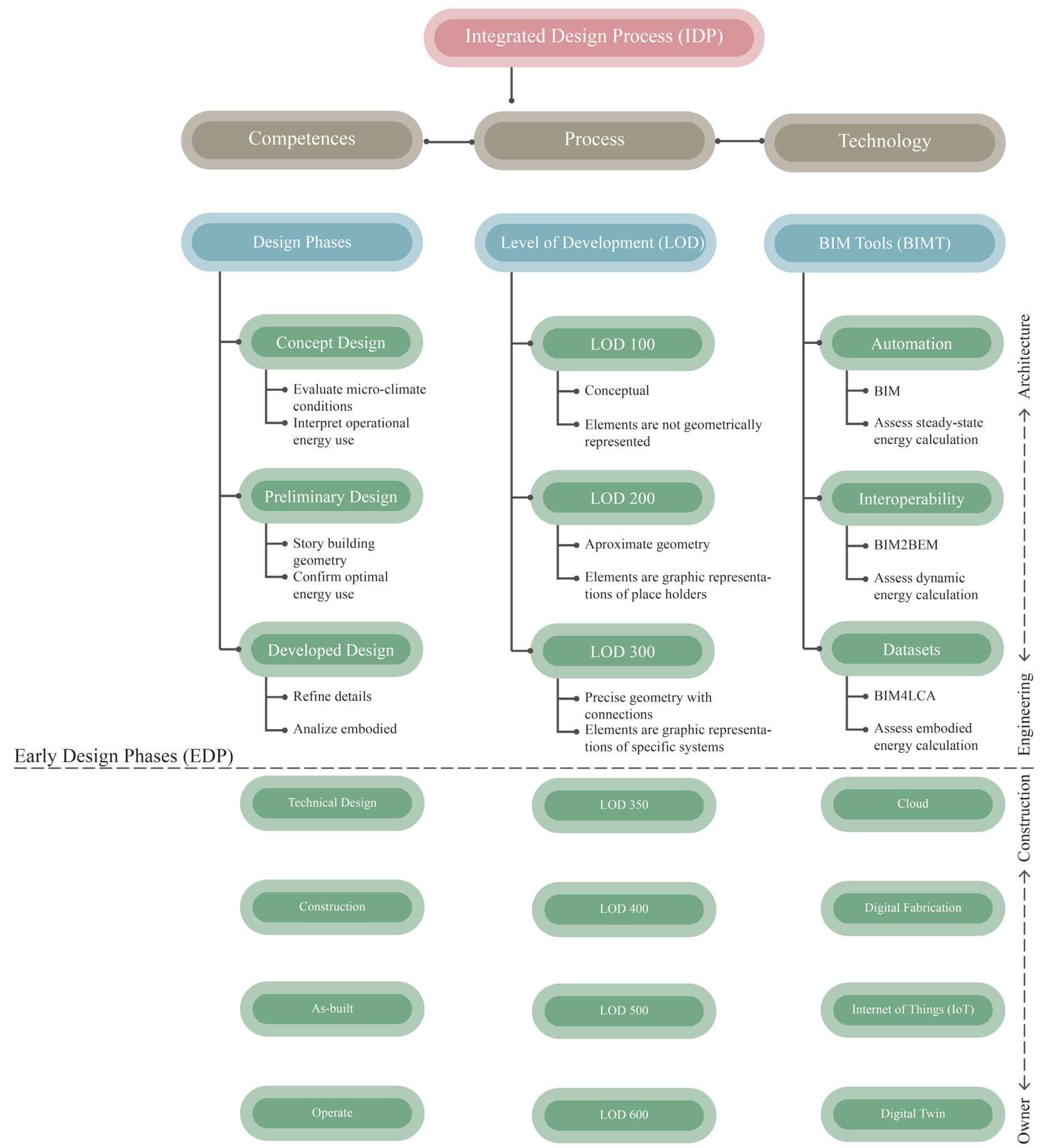

Figure 3. The structure of the themes, subthemes addressed in the scientific literature and topics related to BIM and environmental impact assessment.

\subsection{Early Design Phases}

In their research about front-end definition projects, Samset and Volden [26] maintained that, the potential to reduce uncertainty, which is more important in EDP, diminishes once the project is implemented. They argued that typically, most project planning resources are spent on detailed planning and engineering 
instead of early design stages, where the potential to reduce uncertainty by adding information is the largest. In other words, the majority of resources are used where there is the least potential, during the implementation phase, instead of EDP.

In general, the EDP of a new building project contains three phases:

1) Concept design,

2) Preliminary design, and

3) Developed design.

Here, we include developed design phase in EDP, since it is the phase where geometry is defined, completed by building information and numeric information which are precise. Collaboration between designer, architect and engineer is still needed at this phase. Table 4 shows performance targets according to each design phase from Farzaneh et al. [27].

\subsection{Competences, Process and Technology}

\subsubsection{Competences}

Asl et al. [5] contributed to research on BIM, parametric modeling, and automation as a new trend in sustainable building design. Parametric modeling refers to a modeling process with the capacity to change the shape of geometry at the

Table 4. Performance targets at each design phase, adapted from Farzaneh et al. [27].

\begin{tabular}{|c|c|c|}
\hline $\begin{array}{c}\text { Concept Design } \\
\text { LOD 100-Conceptual }\end{array}$ & $\begin{array}{c}\text { Preliminary Design } \\
\text { LOD 200-Approximate } \\
\text { Geometry }\end{array}$ & $\begin{array}{c}\text { Developed Design } \\
\text { LOD 300-Precise } \\
\text { Geometry }\end{array}$ \\
\hline $\begin{array}{l}\text { Evaluate } \\
\text { micro-climate } \\
\text { conditions }\end{array}$ & $\begin{array}{l}\text { Study building geometry, } \\
\text { spatial configuration, layouts } \\
\text { and wall-to-window ratio } \\
\text { (WWR) to reduce envelope } \\
\text { heat gains and losses }\end{array}$ & $\begin{array}{l}\text { Refine and finalize the } \\
\text { detailed architectural } \\
\text { design from inside to } \\
\text { outside and top to bottom } \\
\text { specifying all characteristics } \\
\text { of the envelope, openings, } \\
\text { constructions types, } \\
\text { materials, layers and } \\
\text { thermal properties }\end{array}$ \\
\hline $\begin{array}{l}\text { Study large scale design } \\
\text { alternatives } \\
\text { (e.g. building masses } \\
\text { and form) }\end{array}$ & $\begin{array}{l}\text { Identify and access the } \\
\text { high-performance options } \\
\text { based on lifecycle cost (LCC) }\end{array}$ & $\begin{array}{l}\text { Complete advanced } \\
\text { analysis of the selected } \\
\text { options (architectural } \\
\text { and mechanical) }\end{array}$ \\
\hline $\begin{array}{l}\text { Investigate building } \\
\text { orientation to } \\
\text { maximize daylighting }\end{array}$ & $\begin{array}{l}\text { Run the preliminary ES to } \\
\text { estimate the heating and } \\
\text { cooling loads }\end{array}$ & $\begin{array}{l}\text { Run the final ES to provide } \\
\text { a detailed and accurate } \\
\text { building energy prediction }\end{array}$ \\
\hline $\begin{array}{l}\text { Evaluate the building } \\
\text { site and topology }\end{array}$ & $\begin{array}{l}\text { Select the Heating Ventilation } \\
\text { Air-Conditioning (HVAC) }\end{array}$ & $\begin{array}{l}\text { Life Cycle Inventory (LCI) } \\
\text { data source }\end{array}$ \\
\hline $\begin{array}{l}\text { Assess steady-state } \\
\text { operational energy } \\
\text { calculation }\end{array}$ & $\begin{array}{l}\text { Assess dynamic operational } \\
\text { energy calculation }\end{array}$ & $\begin{array}{l}\text { Assess embodied energy } \\
\text { calculation }\end{array}$ \\
\hline
\end{tabular}


same time as the dimension value is modified [13]. These new methods to evaluate the performance have opened opportunities to optimize solutions. They presented a case study using a newly developed integrated parametric BIM-based system to interact with ES and daylighting tools to optimize building energy performance. The objective of the case study was to allow architects to explore design alternatives and, at the same time, assess the building performance to search for the most appropriate design. Regarding competences, they stated that ES are complex and most architects do not have enough expertise and knowledge to manage them. To improve building performance, they claimed that architects need to have access to the ES results and the ability to understand and interpret the results. They also mentioned that BIM contains most of the data needed for ES and consequently, these simulations should be moved to the EDP to define the best energy efficiency solution to develop in the next phases. Even though the case study was simple (a residential building), the results demonstrated the potential of using a parametric BIM-based system towards more complex architectural modeling.

Andriamamonjy et al. [28] performed a combined review, scientometric and conventional literature review, to understand the BIM and ES integration as a potential strategy to improve interoperability. They concluded approximately the same as Asl et al., i.e. the available ES software requires manual input and a deep knowledge of the tools' interface, which explains the limited use of ES by architects who lack expertise in the matter. Furthermore, they stated that in case of incomplete data, modelers often have to provide default values established on their knowledge and this default data are seldom documented. For these reasons, the outcome of the ES can vary from a modeler or energy expert to another since the results are dependent on their experience and judgment. Their article revealed some limitations of the BIM2BEM process. For example, they claim that to achieve total interoperability, several issues need to be solved, e.g., data loss, incompatibility, missing information, and the modelers' limited competences.

Arayici et al. [29] research approach on interoperability also indicated that architects are able to perform BIM modeling, but they often have a poor understanding of the information they should share, and at which time, with energy and environmental experts. They adopted the design science methodology approach to encourage early collaboration by developing interoperability specifications. Design4Energy was used as a case study. Design4Energy is a research project funded by the European Union (EU) aiming to develop an innovative and integrated design methodology to predict the current and future energy demand of buildings. They mentioned that architects are also novices in the ES field, which makes it difficult for them to know what information is relevant to experts. Simply put, architects can do BIM modeling, but they have in general very little understanding of what information is relevant and when they should share it with the client and energy experts. The author's approach contributed to the practice knowledge by understanding critical aspects of future projects' interoperability developments in EDP. 


\section{Design Phases}

Jabi [30] outlined that the majority of ES are achieved later in the design phases, when design modifications are difficult to integrate and very costly. Most of the time the ES is conducted to measure compliance with external regulations rather than to fundamentally change the design towards higher performance. For these reasons, Jabi developed and presented a software called DSOS. This tool integrates the use of a parametric design system and an energy analysis engine for the EDP. The software is limited by the amount of time to complete the analysis. Jabi et al. [31] maintained that the ES tools are not architect-friendly, and they are too complex for early design of architecture. The tools are not either compatible with the architects' working methods, which are both more intuitive and iterative. They believe that we need a new way of thinking about modeling in EDP. A few years later, Jabi et al., presented a topologic tool kit based on the DSOS software. Topologic modeling refers to build lighter models that represent space instead of just building fabric, which reduces geometric complexity in ES. The authors concluded that the tool kit needs further investigation and user-testing before being released. Their contribution to parametric and topologic modeling research is an important school of thought. This approach can be appropriate for architects in EDP, where complete BIM is not feasible and not needed.

Picco and Marengo [9], concluded the same as Jabi et al:: EDP design is critical. According to them, if you make poor decisions at the early stages, it is almost impossible to correct them in the next design phases. Despite all the new ES tools that have been created in the last ten years, architects still have difficulty using basic tools supporting EDP decisions. They often simplify the model without paying attention to the consequences of these simplifications. Instead of focusing on developing new software, Picco and Marengo looked in detail at the impact of model simplification on simulation results. The strength of their research was to identify which parts of the model can be simplified without affecting the results. The methodology was based on a previous simplification method by Picco et al. [32] and three different case studies. The results showed that the simplification on the building geometry does not yield a clear difference in the results compared to detailed models if the thermal zone is correctly defined. They also mentioned the need for dynamic ES to increase energy efficiency, but this integration is slowed down by the complexity of ES and the required level of details. There are benefits of applying ES in the EDP. However, the results are limited by the difficulties that arise in the process to define the right level of details at the right phase without compromising the results.

\subsubsection{Process}

Farzaneh et al. [11] found that previous efforts have focused on detailed performance aspects for a particular tool or a detailed design phase instead of addressing the complete design process. Therefore, there appears to be a need to improve the design process by identifying the essential information required at 
each phase. They proposed a BIM-BEM framework using a methodology based on theoretical and field investigations and one case study. The innovation of the proposed framework was not only to focus on the technical aspects, but also, to look at the modeling steps involved in the design process. Subsequently, Farzaneh et al. [27] presented a literature review about BIM2BEM during the design process using a systematic approach. They outlined that each phase requires specific activities with an adequate LOD to run the energy ES, and thereby reach the performance targets established at the beginning of the design process. The authors concluded that further research was needed to fill the academic and professional knowledge gap.

According to Arayici et al. [29], the focus of the AEC industry has been on new tools and methods for improving the quality and structure of information over the project's life cycle. In line with Farzaneh et al., they indicated, that the design process needs increased flexibility and a shared understanding between professionals about which information to share, at which stage, and using which tools and data models for BIM. The authors stated that "we cannot rely on adopting new digital tools such as Grasshopper or Dynamo to improve information using parametric modeling with BIM in the professional practice; this is not sufficient".

Jabi et al. [31] presented a new way of thinking in the initial process, consisting of building the lightest possible model using minimum time and effort to be able to provide relatively accurate results. Their claim supports research by Farzaneh et al. about the importance of adequate LOD. The level of precision of a simulation needs to be compatible with the advancement in the design process. In other words, it would make no sense to build a high precision model when many parameters can still be changed. Precision and time are key aspects to consider in this endeavor. The accurate representation of the building is thus tightly related to time and design phase. There is a need to minimize the simulation time in order to make it compatible with design phase. One way to achieve this goal is to identify and follow the right LOD during the elaboration and development of the design. The authors noted that the full potential of BEM and LCA cannot be exploited at EDP, partly due to a low LOD of BIM.

\section{Level of development}

Building practitioners that are able to integrate performance targets using the right LOD in the EDP will necessarily improve the overall performance of the design. Devoting more time in the EDP in combination of the LOD use and its requirements can improve the level of information and detail in BIM objects. This will lead to fewer interoperability errors since the IFC information will increase.

The lack of ES tools compatible with a low LOD has been outlined as one of the main technology gaps. A model defined at LOD 100 will not allow to conduct, e.g. energy modeling required for a LEED certification. However, recent tools such as Insight (building performance analysis software integrated in Revit) can identify how the building's energy use will influence the outcome and 
propose an interpretation of the results to adjust EDP design and obtain a better chance to meet the certification requirement [33].

With an early contribution about tools development, Andriamamonjy et al. [28]-[34] claimed that performing ES in the EDP with an architectural BIM and a LOD 200 can yield a reduction of energy use of about $20 \%$ from a reference model. Furthermore, they noted that the lack of ES tools compatible with a low LOD emphasizes a technology gap. According to these authors, developing solutions to bridge this gap will be beneficial for building design.

The research of Gomes et al. [12], indicated that LOD 300 is sufficient and compatible with current whole building LCA practice. As a methodology, they selected a case study to support the analysis of the variations between manual quantity assessment from design documents and automatic extraction of data at a suitable LOD level for LCA purposes. The results indicated that automatic extraction could facilitate the process by saving time, reducing data collection effort, and minimizing the risk of errors relative to the manual process. Nevertheless, the authors concluded that there is a possibility that LOD levels lower than 300 can be used during design and preliminary study phases.

Therefore, Nilsen and Bohne [35], suggest that the designers should develop competences with the requirements needed at each LOD level and use average values and best practice where the LOD level is low. Their research assessed LOD to improve the calculation of the environmental impacts at different EDPs more efficiently, using the methodology of LCA. They performed a literature review and a case study to evaluate BIM4LCA in the EDP. Finally, the authors speculated that investing more time in the EDP and using the appropriate LOD can contribute to improve the detail in BIM and reduce errors in BIM4LCA.

\subsubsection{Technology}

Eurac research about regenerative design in digital practice [8] demonstrated that ES tools are designed to make calculations, design and feedback possible, but these workflows remain outside conventional practice, meaning achieving only minimum standards that reduce impact instead of resulting in a positive impact. Moreover, the data analysis is still missing as basic knowledge about sustainable building design. While data are abundant, very little of this data is used to effectively inform the early design of the buildings since there are many other issues to consider by the architects, e.g. concept, context, functions, esthetic, noise, regulations, materials, etc. [36].

The main area we identified to improve the use of data with BIM tools are related to three main subtopics:

1) BIM and automation

Automation means the process of using a computer to perform an operation without involving a human brain [37]. In a review, Kamel and Memari [38], identified automation of modeling processes as one of the major benefits of the application of BIM in ES of buildings, which save time, cost and reduce human errors compared to the conventional energy modeling process. They presented a 
review of research studies focusing on different types of BIM schemes and ES tools capable of reading these files. In addition, they reviewed and analyzed the results of three case studies. Their results showed that many areas still require manual interaction as opposed to automatic data input, e.g. the current BEM tools cannot read the BIM files with minimum errors even if the required data are provided within the file. Anecdotal evidence from architectural practice also reveals that architect firms sometimes perform steady-state energy calculations by manually extracting geometrical data from digital models. In order to improve the transition from manual extraction of data to full automation, we identified LOD 100 as the right level to conduct a steady-state energy calculation towards building code compliance.

2) BIM2BEM and interoperability

In their review and case study, Kamel and Memari [38] also indicated that most issues slowing down the automation process stem from interoperability, which is the degree to which two programs are completely compatible [39]. This interoperability makes the information from BIM applications understandable while providing the possibility to share digital information between the disciplines, which reduces the need for traditional documents. The authors concluded that there is still a long way to reach the objective of performing the BIM2BEM interoperability process with the click of a button.

Andriamamonjy et al. [28]-[34] also identified that the lack of interoperability arises when semantic data (method to structure data to represent it in a logical way) has multiple definitions across different disciplines or when incompatible proprietary information models are used by the collaborators. As outlined by Kamel and Memari [38], even though the use of a standardized data structure such as Industry Foundation Classes (IFC) constitutes a solution, it currently presents a recurrent inconsistency and lack of semantic, which results in information loss. IFC data model is used to describe architectural, building and construction industry data [40]. The format is a scheme widely accepted by the AEC industry to exchange BIM models. It is using layers (resources, core, interoperability and domain) to describe the geometry, material properties and relationships in a BIM model, as mentioned by Farzaneh et al. [11] and Andriamamonjy et al. [28]-[34] concluded data interoperability of BIM with other software packages is presently inefficient, which makes predictions of operational energy use difficult for building practitioners. Part of it is due to the absence of a standard format and differences in data structure among various types of analysis software.

Gerrish et al. [41] outlined that the challenge is the conversion from one tool to the other, which must be performed carefully in order to reduce the risks of model divergence and errors. They developed a method that links design documentation and building performance to identify the technological requirements for BIM and building performance connection in the real world. They supplemented their method with interviews to identify associated behavioral and methodological challenges. In line with Andriamamonjy et al. [28]-[34], they con- 
cluded that the BIM2BEM conversion must be supported by technology to assist the sharing and visualization of ideas in virtual 3D format. Both tools should also be able to support regional regulations and global standards. The major limitation for BIM2BEM integration is the data loss issue, as well as the complexity resulting from employing many tools, especially in the EDP. The limitation of Gerrish et al. research touches the question: "How can information describing the performance of a building be standardized to enable the automated application of tools to provide an accurate representation of energy use? And how could this be supported in context with the common data environment using BIM?" We identified the preliminary design with a specification of LOD 200 as the accurate design phase to complete dynamic energy calculations for the operational energy use and compliance to global standards.

3) BIM4LCA and datasets

Gomes et al. [12] performed research about BIM4LCA using the methodology of a case study. Their results confirmed the need to have embedded environmental parameters and calculation into the model instead of pure material quantities to provide the necessary feedback to accomplish sustainable buildings. In other words, they claim that LCA performance should be calculated through direct access to BIM information. Currently, most of the LCA actually needs other software in addition to BIM. For instance, Revit Architecture is connected to the life-cycle impact assessment tool ATHENA Impact Estimator to investigate negative impacts from the use of several building materials [42]. Similarly, ArchiCad 14 BIM software is connected to Grafisoft EcoDesigner to calculate the carbon footprint [43]. Gomes et al. concluded that this makes predictions of the embodied energy use for the AEC difficult since the second software data interoperability is ineffective and not accessible by the other professionals. One way to make it more effective is to display the embodied energy parameters of building component in the software interface at the developed design phase with a specification of LOD 300. Figure 4 shows an example of the analytical properties interface with data from Revit software where environmental properties can be added e.g., U-value, total climate impact, thermal resistance, solar heat gain and heat transfer coefficient, etc.

A collection of data, referred to as datasets, is one of the most valuable items for future design practices. At the recent AI in AEC conference in Finland, Hjelseth (2021) explained the need for data to be transformed into information by the team of designers, researchers, and scientists, to create a machine learning environment. He claimed that technology, process and people competences are fundamental to integrate a data management technology. Machine Learning is a branch of artificial intelligence (AI), which allows to automatically create models from data. This technology enables computers to learn on their own without having been explicitly programmed by humans to do so. To learn and develop, computers need data to analyze and train on. Data is thus the essence of Machine Learning, and it is seen as the technology that unlocks the full potential of Big Data [44]. Hagström (2021), outlined that it is essential to understand AI on 
M.-F. Stendahl et al.

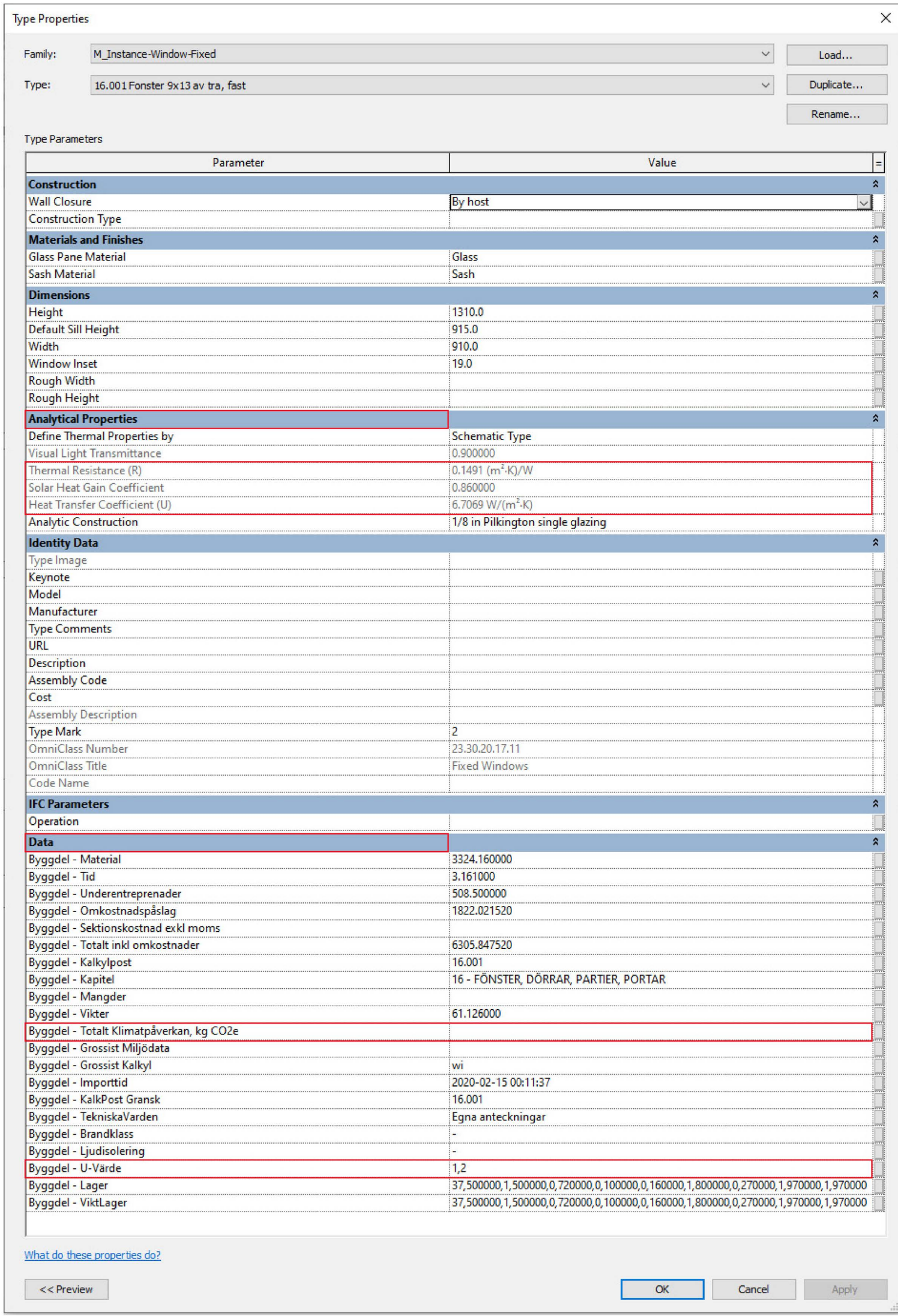

Figure 4. Example of the analytical properties interface with data from Revit software where we can add environmental properties. 
the basic level. She explained that, at the moment, the industry still has problems to understand and analyze data to create algorithms. One of the reasons for this misunderstanding is that data are missing, or their source is unknown.

Besides the three topics discussed in this section, another major issue needs to be addressed by future research, namely, the divergence between the simulated and real energy performance of a building in the operation phase. The discrepancy between the simulated energy performance assessments and the real energy use of a building in the operation phase obviously leads to incorrect BIMbased energy analysis results. Gerrish et al. [41] results showed that the application of BIM to manage building performance during both design and operation is another potential end-goal for the post-construction phase. Reducing the gap between predicted and actual building performance is an area where much effort has been targeted, although BIM as a performance management tool has not been adopted beyond research until now.

\section{Conclusions}

This article presented a review suggesting that BIM, BEM and LCA are relevant developments that will have a key role to play in the future to achieve the necessary reductions of building energy use and GHG emissions towards global climate neutrality. This article presented a literature review on this topic, focusing on information found in the scientific literature. One of the outcomes of this review is that the main themes covered by the scientific literature concern the EDP. Most articles emphasize the need for a more competent use of BIM to perform energy predictions and environmental impact assessment at an EDP, and as a way to encourage stronger collaborations within the AEC industry.

The three main themes that emerge from this review are: 1) competences, 2) processes and 3) technology as discussed below.

Firstly, concerning competences, the literature suggests that BIM users generally have a low level of competence regarding both BIM and ES, which is currently limiting the full potential of the tools available to professionals. The literature suggests that architects, in particular, who produce BIM models seldom understand which information needs to be shared with engineers or environmental experts at each specific design phase. The right LOD needs to correspond to the right performance target to accomplish the appropriate energy performance at each design phase. It thus appears necessary to improve the level of competence of architects both regarding BIM and ES in the future. One of the ways to improve the knowledge of architects is to target the education and courses offered to students in architecture schools. Their understanding of BIM and BEM tools and capacity to interpret results are key to achieve more sustainable design.

Secondly, regarding processes, the literature suggests that processes do not work optimally at the moment due to a low level of understanding of the required LOD in BIM at each design stage. The consequence of this limitation is that professionals are not able to exploit the full potential of BEM and LCA at 
each design phase. Research has indicated that improving the definition and understanding of LOD will facilitate the extraction of the required information from the existing architectural model to perform ES.

Thirdly, concerning the technology of BIM tools, automation, interoperability, and datasets are three areas where improvements are identified in the literature. Automation of process modeling will allow optimization. The current BEM tool cannot read the BIM files with minimum errors and need manual interaction contrasting to automatic data input. Interoperability makes information from BIM applications understandable to exchange data across AEC to empower collaboration. The current data models have recurrent discrepancies and a lack of semantic data, which leads to loss of information during data exchange. Datasets, a collection of data, is one of the most valuable items in future design practices. The literature also points to the need to improve data on environmental properties for performing LCA, through direct access in the BIM model. Currently most of the LCA needs other software in addition to BIM.

Overall, this review suggests that the AEC industry is in need of a concise and straightforward process describing the integration of BIM2BEM and BIM4LCA to follow, especially in the EDP. In addition, this review outlines the knowledge gaps where developments are needed.

The purpose to develop a more integrated methodology with the use of digital tools is to inform design decisions in an efficient, cost-effective way at the EDP. Combining industry and academic knowledge is judged essential in this endeavor, as they both play a role in the development of the methodology to reach more efficient processes. Although the integration of BIM, with BEM and LCA, is key to reach global climate neutrality, there is still limited literature and research in this area. Considerably more work will be needed to ensure a thorough environmental and energy assessment at the EDP. Finally, commercial tools for energy simulations embedded in BIM such as e.g. @Revit Energy Optimization allow performing energy optimization and these tools should obviously be monitored closely in the coming year. Note that these tools are fairly new on the market; they have not been validated yet and a rapid examination reveals that they present limitations regarding a need to follow a certain methodology to be able to perform the calculation without forgetting they are design algorithm that can decide future design.

This research will continue with interviews with practicing professionals to better understand their issues and challenges in the BIM2BEM and BIM4LCA integration. The third step of this research will develop scripts in BIM using a case study from an architecture practice and a control method developed by the academy to automate steady state operational energy assessment, evaluate the best methodology for dynamic energy assessment and improve datasets for more efficient embodied energy assessments.

\section{Conflicts of Interest}

The authors declare no conflicts of interest regarding the publication of this paper. 


\section{References}

[1] World Energy Council (2013) World Energy Scenarios. Composing Energy Futures to 2050 .

[2] International Energy Agency (2015) Building Energy Performance Metrics.

[3] UN Environment and International Energy Agency (2017) Towards a Zero-Emission, Efficient, and Resilient Buildings and Construction Sector. Global Status Report 2017.

[4] UNEP Sustainable Buildings \& Climate Initiative (2009) Buildings and Climate Change: Summary for Decision Makers.

[5] Asl, M.R., Bergin, M. and Menter, A. (2014) BIM-Based Parametric Building Energy Performance Multi-Objective Optimization [Paper Presentation]. Conference: Proceedings of the Conference of Education and Research in Computer Aided Architectural Design in Europe (eCAADe), Newcastle, 10-12 September 2014, 455-464.

[6] Official Journal of the European Union (2012) Directive 2012/27/EU of the European Parliament and of the Council of 25 October 2012 on Energy Efficiency, Amending Directives 2009/125/EC and 2010/30/EU and Repealing Directives 2004/8/EC and 2006/32/EC.

[7] Official Journal of the European Union (2010) Directive 2010/31/EU of the European Parlement and of the Council of 19 May 2010 on the Energy Performance of Buildings. Official Journal of the European Union.

[8] Naboni, E. and Havinga, L. (2019) Accademia europea di Bolzano and Accademia europea di Bolzano. Regenerative design in digital practice. Eurac Research.

[9] Picco, M. and Marengo, M. (2015) On the Impact of Simplifications on Building Energy Simulation for Early Stage Building Design. Journal of Engineering and Architecture, 3, a7. https://doi.org/10.1016/j.tifs.2010.04.009

[10] Sacks, R., Eastman, C., Lee, G. and Teicholz, P. (2018) BIM Handbook: A Guide to Building Information Modeling for Owners, Designers, Engineers, Contractors, and Facility Managers. 3rd Edition, Wiley, Hoboken. https://doi.org/10.1002/9781119287568

[11] Farzaneh, A., Carriere, J., Forgues, D. and Monfet, D. (2018) Framework for Using Building Information Modeling to Create a Building Energy Model. Journal of Architectural Engineering, 24, Article ID: 05018001. https://doi.org/10.1061/(ASCE)AE.1943-5568.0000306

[12] Gomes, V., Barros, N.N. and Ruschel, R.C. (2019) Building Information Modelling for Whole-Building LCA: BIM4LCA. IOP Conference Series. Earth and Environmental Science, 290, Article ID: 012044. https://doi.org/10.1088/1755-1315/290/1/012044

[13] About Building Energy Modeling (n.d.) Energy.Gov. https://www.energy.gov/eere/buildings/about-building-energy-modeling

[14] Brown, G. (1990) The BRIS Simulation Program for Thermal Design of Buildings and Their Services. Energy and Buildings, 14, 385-400. https://doi.org/10.1016/0378-7788(90)90100-W

[15] Koezjakov, A., Urge-Vorsatz, D., Crijns-Graus, W. and van den Broek, M. (2018) The Relationship between Operational Energy Demand and Embodied Energy in Dutch Residential Buildings. Energy and Buildings, 165, 233-245. https://doi.org/10.1016/j.enbuild.2018.01.036

[16] International Energy Agency (2003) Integrated Design Process.

[17] Bruce-Hyrkäs, T. (2021) 7 Steps Guide to Building Life Cycle Assessment or Why 
You Need LCA to Built Sustainably. One Click LCA ${ }^{\oplus}$ Software.

[18] Mamo Fufa, S., Dahl Schlanbusch, R., Sørnes, K., Inman, M. and Andersen, I. (2016) A Norwegian ZEB Definition Guideline.

[19] Dictionary.com (n.d.) Definition of Process. https://www.dictionary.com/browse/process

[20] Dictionary.com (n.d.) Definition of Technology. https://www.dictionary.com/browse/technology

[21] Bertin, I., Mesnil, R., Jaeger, J. M., Feraille, A. and le Roy, R. (2020) A BIM-Based Framework and Databank for Reusing Load-Bearing Structural Elements. Sustainability, 12, 3147. https://doi.org/10.3390/su12083147

[22] The New Zealand BIM Handbook (2019) BIM Media.

[23] Hooper, M. (2015) Automated Model Progression Scheduling Using Level of Development. Construction Innovation, 15, 428-448. https://doi.org/10.1108/CI-09-2014-0048

[24] Marsilio, M., Cappellaro, G. and Cuccurullo, C. (2011) The Intellectual Structure of Research into PPPs. Public Management Review, 13, 763-782. https://doi.org/10.1080/14719037.2010.539112

[25] Royal Institute of British Architects (2020) RIBA Plan of Work 2020 Overview.

[26] Samset, K. and Volden, G.H. (2016) Front-End Definition of Projects: Ten Paradoxes and Some Reflections Regarding Project Management and Project Governance. International Journal of Project Management, 34, 297-313. https://doi.org/10.1016/j.ijproman.2015.01.014

[27] Farzaneh, A., Monfet, D. and Forgues, D. (2019) Review of Using Building Information Modeling for Building Energy Modeling during the Design Process. Journal of Building Engineering, 23, 127-135. https://doi.org/10.1016/j.jobe.2019.01.029

[28] Andriamamonjy, A., Saelens, D. and Klein, R. (2019) A Combined Scientometric and Conventional Literature Review to Grasp the Entire BIM Knowledge and Its Integration with Energy Simulation. Journal of Building Engineering, 22, 513-527. https://doi.org/10.1016/j.jobe.2018.12.021

[29] Arayici, Y., Fernando, T., Munoz, V. and Bassanino, M. (2018) Interoperability Specification Development for Integrated BIM Use in Performance Based Design. Automation in Construction, 85, 167-181. https://doi.org/10.1016/j.autcon.2017.10.018

[30] Jabi, W. (2014) Parametric Spatial Models for Energy Analysis in the Early Design Stages [Paper Presentation]. SIMAUD2014, Tampa, 13-16 April 2014.

[31] Jabi, W., Aish, R., Lannon, S. and Chatzivasileiadi, A. (2018) Topologic: A Toolkit for Spatial and Topological Modelling [Paper Presentation]. Conference: 36th Annual Education and Research in Computer Aided Architectural Design in Europe (eCAADe), Lodz, 19-21 September 2018, 449-458.

[32] Picco, M., Lollini, R. and Marengo, M. (2014) Towards Energy Performance Evaluation in Early Stage Building Design: A Simplification Methodology for Commercial Building Models. Energy and Buildings, 76, 497-505. https://doi.org/10.1016/j.enbuild.2014.03.016

[33] Sustainable_Building_Design_LC95QKQ55GPR (2017, November 3) Project Phases \& Level of Development. Insight|Autodesk Knowledge Network.

[34] Andriamamonjy, A., Saelens, D. and Klein, R. (2018) An Automated IFC-Based Workflow for Building Energy Performance Simulation with Modelica. Automation in Construction, 91, 166-181. https://doi.org/10.1016/j.autcon.2018.03.019 
[35] Nilsen, M. and Bohne, R.A. (2019, September) Evaluation of BIM Based LCA in Early Design Phase (Low LOD) of Buildings [Paper Presentation]. IOP Conference Series. Earth and Environmental Science, Graz, 11-14 September 2019, Vol. 323. https://doi.org/10.1088/1755-1315/323/1/012119

[36] Ruby, I. and Ruby, A. (2010) Re-Inventing Construction. Ruby Press. Berlin.

[37] Dictionary.com (n.d.) Definition of Automation. https://www.dictionary.com/browse/automation

[38] Kamel, E. and Memari, A.M. (2019) Review of BIM's Application in Energy Simulation: Tools, Issues, and Solutions. Automation in Construction, 97, 164-180. https://doi.org/10.1016/j.autcon.2018.11.008

[39] Dictionary.com (n.d.) Definition of Interoperable. https://www.dictionary.com/browse/interoperability

[40] Building SMART International (n.d.) Industry Foundation Classes (IFC). https://www.buildingsmart.org/standards/bsi-standards/industry-foundation-classe $\underline{\mathrm{s}}$

[41] Gerrish, T., Ruikar, K., Cook, M., Johnson, M., Phillip, M. and Lowry, C. (2017) BIM Application to Building Energy Performance Visualisation and Management: Challenges and Potential. Energy and Buildings, 144, 218-228. https://doi.org/10.1016/j.enbuild.2017.03.032

[42] Ajayi, S.O., Oyedele, L.O., Ceranic, B., Gallanagh, M. and Kadiri, K.O. (2015) Life Cycle Environmental Performance of Material Specification: A BIM-Enhanced Comparative Assessment. International Journal of Sustainable Building Technology and Urban Development, 6, 14-24. https://doi.org/10.1080/2093761X.2015.1006708

[43] Tahmasebi, M.M., Banihashemi, S. and Hassanabadi, M.S. (2011) Assessment of the Variation Impacts of Window on Energy Consumption and Carbon Footprint. Procedia Engineering, 21, 820-828. https://doi.org/10.1016/j.proeng.2011.11.2083

[44] Russell, S. and Norvig, P. (2020) Artificial Intelligence: A Modern Approach (Pearson Series in Artificial Intelligence). 4th Edition, Prentice Hall, Hoboken. 